\title{
Radiation Tolerant Digital Signal Processor Transformation'
}

\author{
Steven Sampson \\ Air Force Research Laboratory \\ 3550 Aberdeen Avenue SE \\ Kirtland AFB, NM 87117-5776 \\ 505-846-5816 \\ sampson@plk.af.mil
}

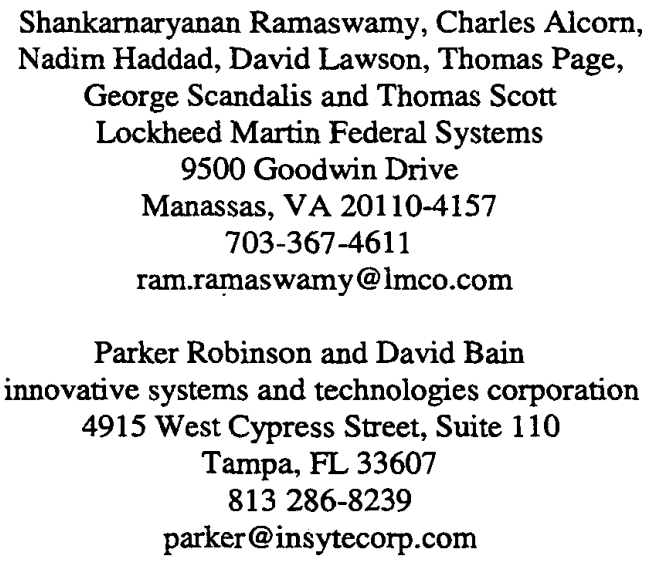

\begin{abstract}
Under the sponsorship of the Air Force Research Laboratory (AFRL) Accelerated Insertion of Standard Microelectronics (AISM) program, Lockheed Martin Federal Systems (LMFS) in Manassas, Virginia, teamed with Analog Devices Incorporated (ADI) of Norwood, Massachusetts. They successfully demonstrated the layout transfer, fabrication and verification of a commercial equivalent Analog Devices Signal Processor (ADSP) 21020 into LMFS's radiation hardened process. This report contains activities related to layout transfer, hardware fabrication, test, and electrical characterization.
\end{abstract}

ADSP-21020 is a widely used floating point digital signal processor (DSP) in commercial applications. The Military Satellite Communications Program Office showed a high level of interest in a Radiation Tolerant Digital Signal Processor (RTDSP) based on the ADSP-21020. A radiation tolerant ADSP-21020 will be an enabling factor in several applications such as image processing, digital filtering and convolution, fast Fourier transforms, data encryption, packet switching, and guidance/navigation processing. In addition, RTDSP can support new space systems applications.

\section{TABLE OF CONTENTS}

\section{INTRODUCTION \\ 2. TECHNOLOGY}

\footnotetext{
${ }^{1}$ U.S. Government work not protected by U.S. copyright.
}

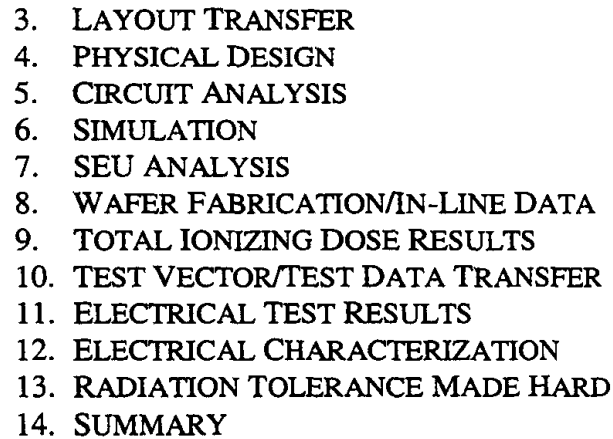

\section{INTRODUCTION}

This effort relies on LMFS's leadership in the radiation hardened Qualified Manufacturing List (QML) process and products, and ADI's leadership in commercial DSPs.

Prominent tasks to implement RTDSP at LMFS include transfer of ADI's ADSP-21020 layout to LMFS's Radiation Hardened Complementary Metal Oxide Semiconductor (RHCMOS) latch-up free process groundrules, fabrication of this design in LMFS's radiation hardened very large scale integration foundry at Manassas, Virginia, and verification of product at test. Figure one shows key milestones throughout the total ionizing dose hardening program phase. 


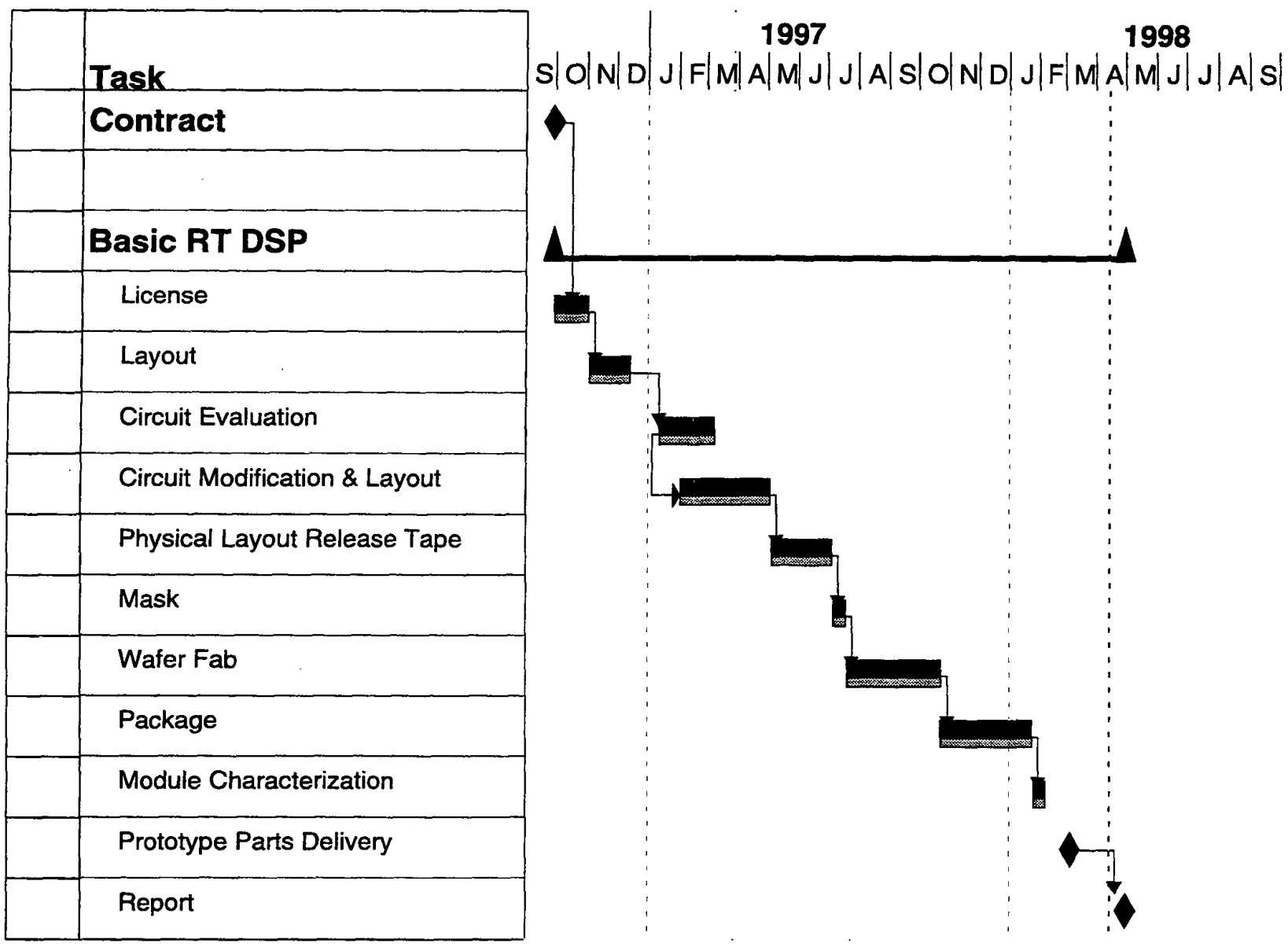

Figure 1 Key Milestones

LMFS worked with ADI to acquire the necessary design information for layout transfer to innovative systems and technologies (insyte) corporation. LMFS coordinated with $\mathrm{ADI}$ and insyte to resolve a number of technical issues during the layout transfer phase of the project.

LMFS worked with Amkor/Anam Test Services to convert the Teradyne J953 test program and patterns for LMFS's T3340 Advantest tester.

LMFS has successfully transferred the ADSP-21020 layout to LMFS's RHCMOS technology which provides the needed radiation total ionizing dose, latch-up immunity and other characteristics that are inherent in LMFS's RHCMOS process. Performance remained the same before or after radiation exposure. Due to the inherent hardness of LMFS process, RTDSP-21020 could satisfy requirements of many applications without a redesign. RTDSP makes possible applications today that were previously impractical because of hardware limitation. Two such applications are on-board image editing and real-time lossless or lossy image compression.
The next step in transforming the ADSP-21020 will be to harden it for single event upsets. One of the more flexible methods will be to transfer the netlist for the ADSP-21020 into a LMFS application specific integrated circuit (ASIC) containing the hardened circuit elements. Thus, the single event upset hardened version of the RTDSP can reside as a macro element within LMFS's ASIC library. This allows an embeddable DSP core to be realized in semi-custom DSP devices. These ASIC DSPs may provide multi-processing on shrinking feature size processes while coupling on-chip memory or pre/post processing algorithm functions. Finally, a floating point, software compatible DSP core will then be available for the tolerant military or commercial space electronics market.

The technical approach to develop a radiation tolerant version of the ADSP-21020 included the following tasks:

(1) transferring ADI's commercial 21020 DSP layout to LMFS's QML RHCMOS-4E process layout rules,

(2) verifying the layout transfer through extensive layout rule checks on the ADI re-hosted graphics, 
(3) simulating extensive analog circuit analysis,

(4) fabricating prototype DSP parts for evaluation in RHCMOS-4E technology,

(5) re-hosting ADSP-21020's test vectors and characterization data from the Teradyne J953 tester to LMFS's Advantest T3340 very large scale integration (VLSI) tester,

(6) performing total dose testing on RTDSP-21020 test structures, and

(7) performing hardware functional verification and characterization.

\section{TECHNOLOGY}

During the development of LMFS's radiation hardened technology, LMFS kept compatibility with International Business Machine's (IBM) commercial technologies a top priority. This strategy was key to their being able to transfer IBM's 1.0 micron, 0.7 micron, and 0.5 micron commercial CMOS processes to the LMFS foundry in Manassas, Virginia. Each of these radiation hardened processes is fully compatible with their corresponding commercial counterparts. Thus, LMFS can readily transfer many commercial VLSI designs to its radiation hardened VLSI foundry without redesign. For the ADSP-21020, the technology selected was 0.8 micron RHCMOS-4E utilizing fully planar back-end-of-line interconnect metallurgy. Commercial ADSP-21020 is implemented in 0.6um CMOS technology.

These are the features of RHCMOS-4E radiation hardened technology that enables design transparency.

\section{Total Dose}

The innovative hardening of Local Oxidation Of Silicon (LOCOS) isolation is the key to total dose hardening. This eliminates parasitic leakage while preserving layout rules and vertical topology, and enables the use of commercial designs without alteration. Further hardening of gate oxide reduces sensitivity to ionizing radiation and minimizes threshold shifts.

\section{Dose Rate Upset}

Use of very thin epitaxial layer and high energy implanted retrograde $\mathrm{N}$-well helps reduce photo current collection at circuit nodes, and enhances dose rate upset levels to the highest of any bulk CMOS technology.

\section{Latch-Up}

The retrograde $\mathrm{N}$-well design, coupled with the thin epitaxial layer and enhanced field process, assures latch-up immunity by reducing bipolar parasitics and series resistance.

\section{Survivability}

Latch-up immunity, limited photo current collection, electromigration resistant metallurgy schemes, as well as contact barrier metallurgy assures survivability at the highest dose rates available.

\section{Single Event Upset (SEU)}

Standard commercial designs benefit significantly from fabrication with the LMFS radiation hardened processes. Depletion regions are limited and charged particle funnels are truncated by the high concentration substrate, thus limiting charge collection at circuit nodes. Threshold linear energy transfer is extended by three to five times for the same circuits when fabricated with the LMFS process. This in itself satisfies requirements of many applications.

\section{LAYOUT TRANSFER}

The task of layout conversion of ADSP-21020 to LMFS's RTDSP-21020 was contracted to insyte corporation. Weekly telecons, and internal design reviews were held between LMFS and insyte corporation to address action items and issues. A formal design review was held between LMFS, insyte and ADI to review the results of the layout transfer task to ensure the success of the activity.

\section{PHYSICAL DESIGN}

LMFS successfully demonstrated the layout transfer activity by producing ADI's ADSP-21020 with LMFS's RHCMOS$4 \mathrm{E}$ process. This was achieved through a thorough review of ADI's layouts and layout rules as well as the electrical parameter requirements and the LMFS RHCMOS process and layout rules. All mask layers and the lithography alignment schemes were defined along with the mask manufacturing specifications.

LMFS also designed the frame and the scribe line (kerf) structures to assure that ADI's chip layout data and the test site design can be successfully converted into mask reticles for device fabrication.

The layout transfer activity consisted of the following:

(1) A layer re-map process,

(2) A layer adjustment process,

(3) A feature shrinking process, and

(4) A correction process for RHCMOS-4E design violations.

The entire re-hosting process was performed using Cadence layer map tables and skill programs and hence was fully automated. Design Rule Check (DRC) was performed on the re-hosted graphics and resulted in a total of nine errors. These errors related to the alphanumerics used in the logo and were no impact to the functionality of the chip and 
hence were waivered. Figure two shows a high level block diagram of the ADI DSP to LMFS re-host methodology. Total transistor count for the DSP was 331,192. This translated to an equivalent gate count of 82,798 (using four transistors per gate as the industry standard method of computing the equivalent gate count).

\section{CIRCUIT ANALYSIS}

Another significant aspect of the layout transfer included the review of critical circuits used in ADSP-21020. A design element matrix was developed to guide the process of searching for potential critical circuits. Table one summarizes the findings.

Each of the 798 schematics supplied by ADI were computer analyzed for the presence of capacitors, resistors, diodes, $\mathrm{N}$ channel (N-ch) field effect transistors (FET) and P-channel (P-ch) FET circuit elements. These schematics were then printed and then visually inspected. There were 196 schematics in 23 libraries which have these primitive components.

\section{Simulation}

In order to alleviate an analog circuit conversion within a digital device process concern due to the use of the phase lock loop (PLL), LMFS performed a simulation of the ADI PLL circuit using LMFS RHCMOS-4E technology parameters. Figure three shows block diagram of the PLL used on the 21020 chip.

PLL functionality and characteristics were evaluated and compared to ADI's results. Results of the simulation showed that LMFS waveforms and simulation results matched ADI's results and the phase relationships and performance of the PLL were maintained.

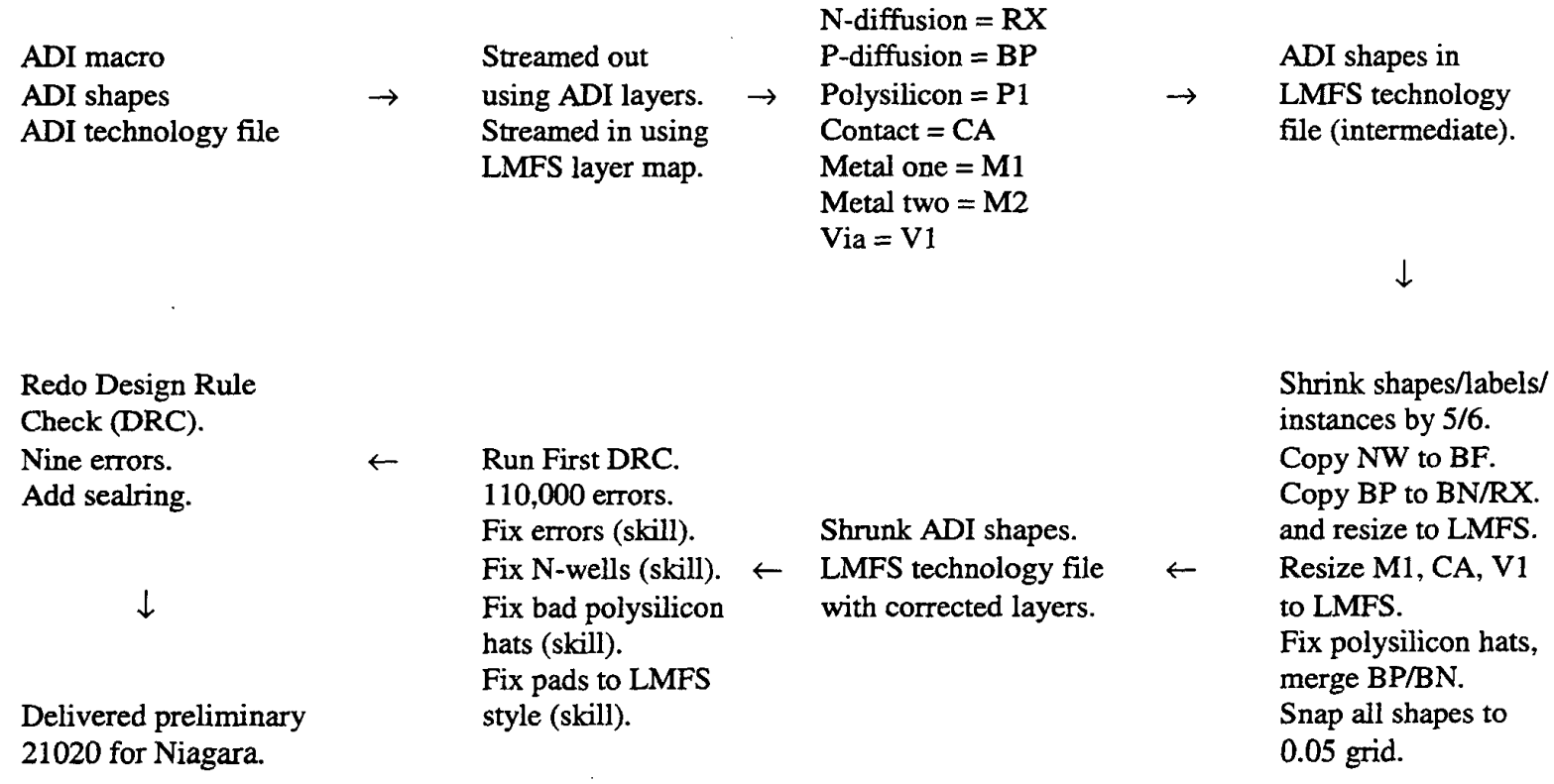

Figure $2 \mathrm{ADI} 21020$ DSP to LMFS Re-host 
Table 1. Design Element Matrix

\begin{tabular}{|c|c|c|c|c|c|}
\hline Design Issue & $\begin{array}{l}\text { Combinational } \\
\text { Logic }\end{array}$ & $\begin{array}{l}\text { Combinational } \\
\text { with Passgates }\end{array}$ & $\frac{\text { Pure Analog like }}{\text { PLL (AC Only) }}$ & $\begin{array}{l}\text { Analog Latch } \\
\text { With Passgates }\end{array}$ & $\begin{array}{l}\text { Analog Input } \\
\text { Output }\end{array}$ \\
\hline $\begin{array}{l}\text { Drive Current/ } \\
\text { Voltage } \\
\text { Function of Voltage } \\
\text { Fu PFET to NFET } \\
\text { Ratios }\end{array}$ & $\begin{array}{l}\text { Function Okay } \\
\text { - Affects Power } \\
\text { - Affects } \\
\text { Performance }\end{array}$ & $\begin{array}{l}\text { Possible } \\
\text { Functional Issue } \\
\text { - Multiplexers } \\
\text { - Registers } \\
\text { - Affects Power } \\
\text { Performance } \\
\text { SEVERTY: Low }\end{array}$ & $\begin{array}{l}\text { Possible } \\
\text { Functional Issue }\end{array}$ & $\begin{array}{l}\text { Possible } \\
\text { Functional Issue } \\
\text { - LATD } \\
\text { - RFBIT } \\
\text { - CABIT } \\
\text { - RFXBARBIT } \\
\text { - Etc. } \\
\text { SEVERTY: Low }\end{array}$ & $\begin{array}{l}\text { Function Okay } \\
\text { Consider Package } \\
\text { Performance } \\
\text { SEVERITY: Very Low }\end{array}$ \\
\hline $\begin{array}{ll}\text { Parasitic } \\
\text { Capacitor } \\
\text { - } \quad \text { Diffusion } \\
\text { - } \quad \text { Gate } \\
\text { - } \quad \text { Wire }\end{array}$ & $\begin{array}{l}\text { Function Okay } \\
\text { - Affects Power } \\
\text { Performance }\end{array}$ & $\begin{array}{l}\text { Possible } \\
\text { Functional Issue } \\
\text { - Multiplexers } \\
\text { - Registers } \\
\text { - Affects Power } \\
\text { Performance } \\
\text { SEVERTY: Low }\end{array}$ & $\begin{array}{l}\text { Possible } \\
\text { Functional Issue }\end{array}$ & $\begin{array}{l}\text { Possible } \\
\text { Functional Issue } \\
-\quad \text { Affects Power } \\
\text { Performance } \\
\text { SEVERITY: Low }\end{array}$ & $\begin{array}{l}\text { Function Okay } \\
\text { - Affects Power } \\
\text { Performance }\end{array}$ \\
\hline $\begin{array}{l}\text { Electrostatic } \\
\text { Discharge } \\
\text { (ESD) Diode }\end{array}$ & $\begin{array}{l}\text { Not Applicable } \\
\text { (NA) }\end{array}$ & NA & NA & NA & $\begin{array}{l}\text { Function Okay } \\
\text { - Affects Testing } \\
\text { If Too Low ESD } \\
\text { Protection }\end{array}$ \\
\hline $\begin{array}{l}\text { Capacitor } \\
\text { - CAPMOS } \\
\text { - Plate } \\
\text { (Polysilicon/Metal) }\end{array}$ & NA & NA & $\begin{array}{l}\text { Possible } \\
\text { Functional Issue } \\
\text { - CAPMOS Used } \\
\text { To Adjust Loading in } \\
\text { Delay Line } \\
\text { SEVERTY: Low }\end{array}$ & NA & NA \\
\hline
\end{tabular}

Notes: SEVERITY: Very Low. The design team recognized that circuit performance or function could be affected by the cited design issue: the design team did not believe it would be observed.

SEVERITY: Low. The design team believed that there is a low risk that circuit behavior will be adversely affected by the issue.

SEVERITY: Medium. The design team believe that there is significant risk that circuit behavior will be adversely affected by the issue.

SEVERITY: High. The design team believed that the circuit behavior will be adversely affected by the issue.

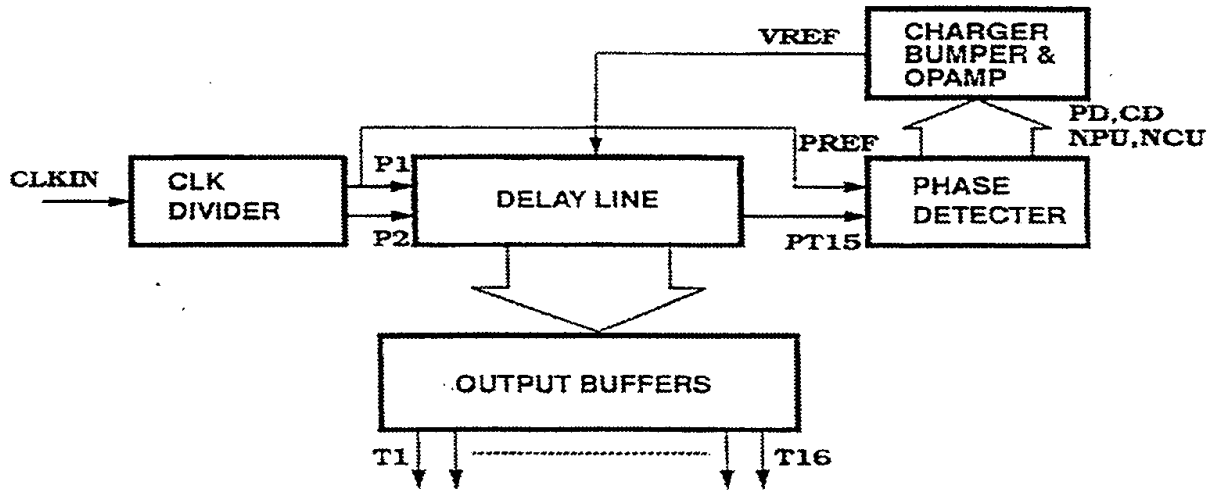

Figure 3 PLL Block Diagram 


\section{SEU ANALYSIS}

A Critical Charge $\left(Q_{\text {crit }}\right)$ analysis was done on all the storage elements in the 21020 chip to estimate the SEU rates. Refer to Table two for a summary of the Qcrit results.

\section{WAFER FABRICATION/IN-LINE DATA}

Wafer fabrication of RTDSP-21020 completed successfully in LMFS's VLSI foundry. The in-line electrical data of the lot consisting of parametric and defect parameters was gathered at the Post Aluminum Probe (PAP) and Post Nitride Probe (PNP). The test site data in Table three showed that the key process parameters [delta $(\Delta)$ length $(\mathrm{L})$, threshold voltage (Vt), drive currents, etc.] were well within specification and were centered around the mean.

\section{TOTAL IONIZING DOSE RESULTS}

One wafer from the lot was tested for total ionizing dose radiation response. The total ionizing dose testing exposed test sites on the wafer to an ionizing radiation environment. Equipment used for radiation testing at LMFS is from Advanced Research and Applications Corporation (ARACOR). The devices were exposed to a total dose radiation of $2 \mathrm{Mrad}(\mathrm{Si})$ to guarantee a specification of $1 \mathrm{Mrad}(\mathrm{Si})$. The permanent effects of total ionizing dose radiation are the negative $\mathrm{Vt}$ shifts, reduction in transconductance due to carrier trapping sites along the oxide-silicon interface, and increase in $\mathrm{N}$-ch leakage currents. N-ch FET and P-ch FET devices on the test sites were measured for shifts in threshold voltages, input/output voltages, and channel leakage currents. Current leakage was $10^{-10} \mathrm{~A}$ against a specification of $<2.7 \times 10^{-10} \mathrm{~A}$ at $1 \mathrm{Mrad}$ (Si). Table four shows $\Delta \mathrm{Vt}$ from total ionizing dose.
Worst Case Process, $4.5 \mathrm{~V}, 20^{\circ} \mathrm{C}$

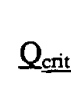

$0.2 \mathrm{pC}$
$0.2 \mathrm{pC}$
$0.7 \mathrm{pC}$
$0.2 \mathrm{pC}$

RAM Cells

Register File Cells

Latch Cells (LATD-1X)

Latch Cells (MLAT, PSJL)

Total

Typical Requirement:

Table 2. SEU Analysis Summary SEU Estimate upsets/bit-day

Cell Number

4224

1280

1008

683

7195
SEU Rate upsets/device-day

$4.22 \mathrm{E}-3$

$1.24 \mathrm{E}-3$

$0.10 \mathrm{E}-3$

$1.46 \mathrm{E}-3$

7.52 E-3

$<4.0 \mathrm{E}-6$

Notes: LATD: Latch with Local Refresh Decode MLAT: Latch with Multiplexed Inputs PSJL: Program Sequence Jam Latch

Table 3. Summary of Key In-Line Electrical Data (Parametric)

Parameter
$\Delta \mathrm{L} N$-ch
$\Delta \mathrm{L}$ P-ch
Vt N-ch
Vt P-ch
Ids N-ch
Ids P-ch
Ioff N-ch
Ioff P-ch

Device Type

N-ch FET (2.7um width/1.3um L)

P-ch FET (2.7um width/1.3um L)

$\begin{array}{ll}\frac{P A P}{0.30 \mathrm{um}} & \frac{\text { PNP }}{0.27 \mathrm{um}} \\ 0.19 \mathrm{um} & 0.21 \mathrm{um} \\ 0.78 \mathrm{~V} & 0.77 \mathrm{~V} \\ -0.89 \mathrm{~V} & -0.89 \mathrm{~V} \\ 16.56 \mathrm{~mA} & 16.90 \mathrm{~mA} \\ 7.58 \mathrm{~mA} & 7.93 \mathrm{~mA} \\ 0.04 \mathrm{nA} & 0.07 \mathrm{nA} \\ 0.09 \mathrm{nA} & 0.05 \mathrm{nA}\end{array}$

Specification Mean

0.32 um

$0.25 \mathrm{um}$

$0.78 \mathrm{~V}$

$-0.89 \mathrm{~V}$

$16.50 \mathrm{~mA}$

$7.80 \mathrm{~mA}$

$<5.0 \mathrm{nA}$

$<5.0 \mathrm{nA}$
Table 4. Total Ionizing Dose Results

$$
\begin{aligned}
& \Delta V_{t} \text { Shift } \\
& -135 \mathrm{mV} \\
& -195 \mathrm{mV}
\end{aligned}
$$

$\Delta \mathrm{Vt} \mathrm{Spec}$

$-300 \mathrm{mV}$

$-300 \mathrm{mV}$ 


\section{Test Vector/Test Data Transfer}

The task of test data conversion was contracted to Amkor/Anam Test Services. The three main objectives of the test data conversion were to (i) convert test data from a Teradyne tester format to an Advantest tester format, (ii) build a test fixture and (iii) demonstrate test. Test programs and patterns were supplied to LMFS on tape from ADI.

LMFS worked closely with Amkor/Anam Test Services to accomplish the following:

(1) design and build performance boards with sockets,

(2) convert a total of 98 tests which included test programs and test pattern sets from Teradyne tester format to Advantest platform, and
(3) test 22 commercial "golden" modules with identical results on both testers on 90 out of the 98 tests.

\section{Electrical test Results}

LMFS tested RTDSP-21020 wafers using the converted test programs and patterns. Due to lack of funding on the program, a complete debug of the test programs and test patterns could not be completed. Following is a summary of test results for the RTDSP-21020 modules tested on the LMFS Advantest tester in Table five and the ADI Teradyne tester in Table six.

Table 5. LMFS Tests

Module Number

\section{Golden}

$\begin{array}{llllllllllllllllllll}\text { Module } & 1 & 2 & 3 & 4 & 5 & 6 & 7 & 8 & 9 & 10 & 11 & 12 & 13 & 14 & 15 & 16 & 17 & 18 & 19\end{array}$

(ADSP 21020)

Shorts

Input Leakage Low

Input Leakage High

Mass Functional
$\mathbf{X}(\mathbf{P i n} \mathrm{P} 17)$

$\mathbf{X} \mathbf{X}$
$\mathbf{X}(\mathbf{P}$ in $\mathrm{K} 01)$

$\mathbf{X}($ Pins SO5,KO5)

\begin{tabular}{|c|c|c|c|c|c|c|c|c|c|c|c|c|c|c|c|}
\hline $\begin{array}{l}\text { Basic Functional } \\
\text { FLOATAL5 (VddMin) }\end{array}$ & $\mathbf{x}^{(1)}$ & $\mathbf{X}$ & $\mathbf{y}$ & $\mathbf{x}$ & $\mathbf{x}$ & $\mathbf{x}$ & $\mathbf{x}$ & $\mathbf{x}$ & $\mathbf{x}$ & $\mathbf{x}$ & $\mathbf{x}$ & $\mathbf{X}$ & $\mathbf{x}$ & $\mathbf{x}$ & $\mathbf{x}$ \\
\hline JTAG (VddMin) & $\mathbf{X}$ & $\mathbf{X}$ & $\mathbf{X}$ & $\mathbf{X}$ & $\mathbf{X}$ & $\mathbf{X}$ & $\mathbf{X}$ & $\mathbf{X}$ & $\mathbf{X}$ & $\mathbf{X}$ & $\mathbf{X}$ & $\mathbf{x}$ & $\mathbf{X}$ & $\mathbf{X}$ & $\mathbf{X}$ \\
\hline JTAG (VddMax) & $\mathbf{X}$ & $\mathbf{X}$ & $\mathbf{X}$ & $\mathbf{X}$ & $\mathbf{X}$ & $\mathbf{X}$ & $\mathbf{X}$ & $\mathbf{X}$ & $\mathbf{X}$ & $\mathbf{X}$ & $\mathbf{X}$ & $\mathbf{X}$ & $\mathbf{X}$ & $\mathbf{X}$ & $\mathbf{X}$ \\
\hline ADDITIONAL VddMin ${ }^{(2)}$ & & & & $\mathbf{X}$ & & & & & & & & & & & \\
\hline ADDITIONAL VddMax ${ }^{(2)}$ & & $\mathbf{X}$ & $\mathbf{X}$ & $\mathbf{X}$ & $\mathbf{X}$ & $\mathbf{X}$ & $\mathbf{X}$ & $\mathbf{X}$ & $\mathbf{X}$ & $\mathbf{X}$ & $\mathbf{X}$ & $\mathbf{X}$ & $\mathbf{X}$ & $\mathbf{X}$ & $\mathbf{X}$ \\
\hline Complex Functional & & & & & & & & & & & & & & & \\
\hline MULT1F (VddMin) & $\mathbf{X}$ & $\mathbf{X}$ & $\mathbf{X}$ & $\mathbf{X}$ & $\mathbf{X}$ & $\mathbf{X}$ & $\mathbf{X}$ & $\mathbf{X}$ & $\mathbf{X}$ & $\mathbf{X}$ & $\mathbf{X}$ & $\mathbf{X}$ & $\mathbf{X}$ & $\mathbf{X}$ & $\mathbf{X}$ \\
\hline MULT1F (VddMax) & $\mathbf{X}$ & $\mathbf{X}$ & $\mathbf{X}$ & $\mathbf{X}$ & $\mathbf{X}$ & $\mathbf{X}$ & $\mathbf{X}$ & $\mathbf{X}$ & $\mathbf{X}$ & $\mathbf{X}$ & $\mathbf{X}$ & $\mathbf{X}$ & $\mathbf{X}$ & $\mathbf{X}$ & $\mathbf{X}$ \\
\hline Control Tests (VddMin) & $\mathbf{X}$ & $\mathbf{x}$ & $\mathbf{X}$ & $\mathbf{X}$ & $\mathbf{X}$ & $\mathbf{X}$ & $\mathbf{X}$ & $\mathbf{X}$ & $\mathbf{X}$ & $\mathbf{x}$ & $\mathbf{X}$ & $\mathbf{X}$ & $\mathbf{X}$ & $\mathbf{X}$ & $\mathbf{X}$ \\
\hline ADDITIONAL VddMin ${ }^{(2)}$ & & & $\mathbf{x}$ & & & & & & & & & & & & \\
\hline Control Tests (VddMax) & $\mathbf{X}$ & $\mathbf{X}$ & $\mathbf{X}$ & $\mathbf{X}$ & $\mathbf{X}$ & $\mathbf{X}$ & $\mathbf{X}$ & $\mathbf{X}$ & $\mathbf{X}$ & $\mathbf{X}$ & $\mathbf{X}$ & $\mathbf{X}$ & $\mathbf{X}$ & $\mathbf{X}$ & $\mathbf{X}$ \\
\hline ADDITIONAL VddMax ${ }^{(2)}$ & & $\mathbf{x}$ & $\mathbf{X}$ & $\mathbf{X}$ & $\mathbf{X}$ & $\mathbf{X}$ & $\mathbf{X}$ & $\mathbf{X}$ & $\mathbf{X}$ & $\mathbf{X}$ & $\mathbf{X}$ & $\mathbf{X}$ & $\mathbf{X}$ & $\mathbf{X}$ & $\mathbf{X}$ \\
\hline
\end{tabular}

Notes: (1) An " $\mathrm{X}$ " represents a module failing a particular test. All modules tested at $25^{\circ} \mathrm{C}$ only.

(2) Additional failing tests on the "Golden Module" could be attributed to test pattern conversion and tester differences between Teradyne and Advantest testers. 
Table 6. ADI Tests

Module Number

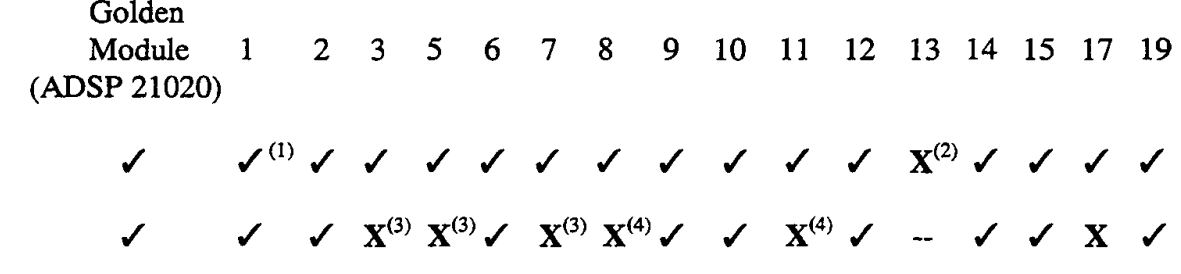

DC Parametric
Functional, Control
and Alternating
Current (AC) Tests

Notes: (1) " $\checkmark$ " represents a passing module. Tested at Vdd $\pm 10 \%$ at $-55^{\circ} \mathrm{C}, 25^{\circ} \mathrm{C}$ and $125^{\circ} \mathrm{C}$.

(2) Input Leakage High fails.

(3) Multiple Functional and Control Test fails.

(4) Marginal fail for Joint Test Action Group (JTAG) test. Module passed without JTAG test.

\section{ElECTRICAL CHARACTERIZATION}

Electrical characterization was performed at $\mathrm{ADI}$ on all the nine modules that passed all of the functional, control and AC tests. The parts were characterized across Vdd and temperature.

LMFS collected worst case summary data across temperature and voltage for $20 \mathrm{MHz}$ and $25 \mathrm{MHz}$ operation. Actual data values were compared to determine margin with respect to commercial ADSP-21020 specifications.

Figure four is a voltage graph for $25 \mathrm{MHz}$ operation. This graph shows the operations range of the RTDSP-21020 across the $5 \mathrm{~V} \pm 10 \%$ power supply limits. It was found that at the worst case conditions of $4.5 \mathrm{~V}$ and $125^{\circ} \mathrm{C}$, the performance mean was around $26 \mathrm{MHz}$.

Figure five is a temperature relative graph. This graph shows the operating range of a RTDSP-21020 across $-55^{\circ} \mathrm{C}$, $25^{\circ} \mathrm{C}$ and $125^{\circ} \mathrm{C}$. Here again, it was found that under the worst case condition of $125^{\circ} \mathrm{C}$ and $4.5 \mathrm{~V}$, the performance mean was around $26 \mathrm{MHz}$.

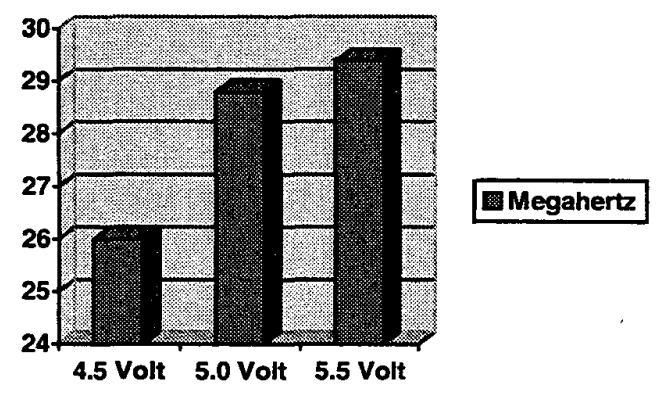

Figure 4 Maximum Frequency versus Voltage

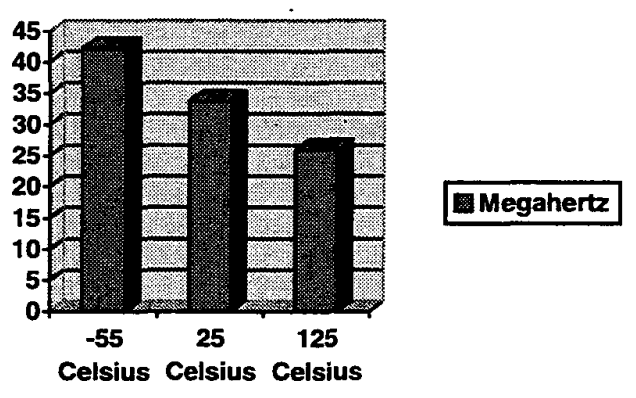

Figure 5 Maximum Frequency versus Temperature

\section{RADIATION TOLERANCE MADE HARD}

Because of the limitations achieved in radiation tolerance via the geometric layout transformation, a netlist hardened design must be initiated to achieve greater radiation hardness. For two years the AFRL has advertised via the Commerce Business Daily the need for "...applied development in optoelectronic and photonic technologies with relevant device hardening, advanced hardened circuit technology such as ... other space qualified compiler programmable digital ASIC cores like an ASDP-21020." Further hardening developments for this device can occur under the auspices of the Technology License Agreement (TLA), Lockheed Martin “...License of Analog Devices' ADSP-21020 DSP for Fabrication of Radiation Tolerant Devices."

The Advanced Spaceborne Computer Module contract with LMFS developed several hardened ASICs for both the Control Processor Module and Advanced Technology Insertion Module program phases. It is possible to create an embeddable DSP ASIC macro library element that leverages 
the improved design upset hardness found within LMFS' standard cell technology. The RTDSP-21020 ASIC core would still use the software compilers available allowing true "system-on-a-chip" performance. With minor clarifications within the TLA, even on-chip multiprocessing and embedded memory could enhance the real-time processing throughput of these semi-custom DSPs.

Continued evolution of LMFS RHCMOS processes can also be leveraged using this netlist to ASIC library module approach. The RTDSP-21020 would no longer be constrained to only a single feature size with each geometric layout transfer. Migration to deep submicron technology would be transparent to the end user as LMFS' library conversions would take into account process transfer design dependencies. Other real-time processing functions like fast Fourier transforms or sample and hold functions can be easily integrated on-chip by using the features available within the ASIC library.

The LMFS/insyte team is highly qualified to make this paradigm shift from fully custom DSP algorithm ASICs and programmable plug-in compatible DSP to the embedded DSP core library option. This technology can retain an almost indefinite shelf life when made a selectable element for quick-turn ASIC device solutions. Possibly, dial-in hardness may allow easier export of this technology with approval granted for devices created for domestic or offshore customers independently. However, if at some future point this technology would no longer be available from LMFS the TLA might transfer to Honeywell, Allied Signal, Northrop Grumman or Hughes Aircraft Company.

\section{SUMMARY}

Under the sponsorship of the Air Force Research Laboratory AISM program, LMFS successfully demonstrated the layout transfer, fabrication and verification of a commercial equivalent ADSP-21020 into LMFS's RHCMOS-4E process. Performance remained the same before or after radiation exposure.

LMFS worked with $\mathrm{ADI}$ to acquire the necessary design information for layout transfer to insyte. LMFS coordinated with $\mathrm{ADI}$ and insyte to resolve a number of technical issues during the layout transfer phase of the project.

LMFS worked with Amkor/Anam Test Services to convert Teradyne J953 test program and patterns for LMFS's T3340 Advantest tester.

LMFS has successfully transferred the ADSP-21020 layout to LMFS's RHCMOS technology which provides the needed radiation total ionizing dose, latch-up immunity and other characteristics that are inherent in LMFS's RHCMOS process. Due to the inherent hardness of LMFS's process, RTDSP-21020 could satisfy requirements of many applications without a redesign.
The next generation of real-time DSP functions may come from a follow-on to this program with the advent of embeddable ASIC cores. Proposals desired by AFRL will leapfrog floating point technology into radiation robust applications even before it is available in the commercial ASIC market. We expect to continue this technology into the newest devices from LMFS that will be used in future aerospace systems.

Steven Sampson is a Test and Evaluation Electronics Engineer the Air Force Research Laboratory, Space Vehicles Directorate, Phillips Research Site. $\mathrm{He}$ is primarily responsible for developing digital and analog signal

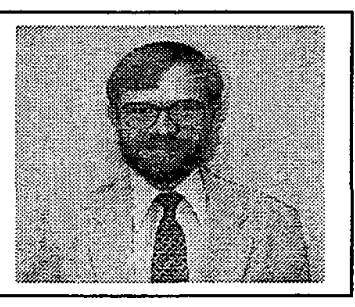
processing electronics used in space and missile systems. His research applies novel independent verification and validation techniques to demonstrate improved hardened electronics device reliability. He attained a Bachelor of Electrical Engineering degree with distinction from the University of Minnesota and a MSEE at the New Mexico State University.

\begin{abstract}
Ram Ramaswamy is a Product Engineer for Lockheed Martin Federal Systems in the VLSI organization. He is the lead product engineer for the radiation hardened DSP and memory products for commercial and military space applications. He has over 15

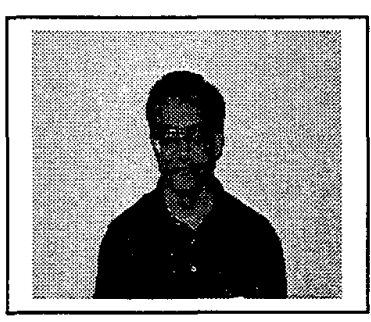
years of experience in the semiconductor field in the areas of Product Development, Product Engineering, test and characterization at IBM, Loral and Lockheed Martin. He holds MS degree in Electrical Engineering from University of Kentucky.
\end{abstract}

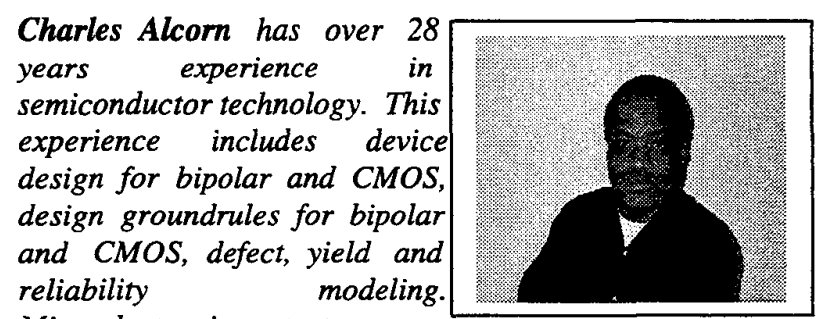
Microelectronic test structures are his current specialty. He is an active member of the program committee of the 'IEEE International Conference on Microelectronic Test Structures'. He holds degrees from Occidental College in Los Angeles and Howard University in Washington DC. 
Nadim Haddad is a Senior Technical Staff Member at Lockheed Martin Federal Systems, Manassas, Virginia. $\mathrm{He}$ is currently the chief engineer for the 4M RH SRAM development, and principal investigator for VLSI product development IR\&D, and was

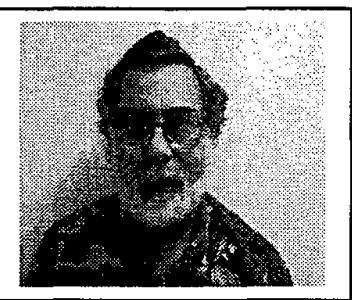
instrumental in the development of radiation hardened technologies and products over the years at IBM, Loral and Lockheed Martin. He received a BA in physics and mathematics from Kansas Wesleyan University (1965), and a MS in electrical engineering from Michigan State University (1966). He holds 12 patents and has over 40 publications. He is a Senior Member, IEEE.

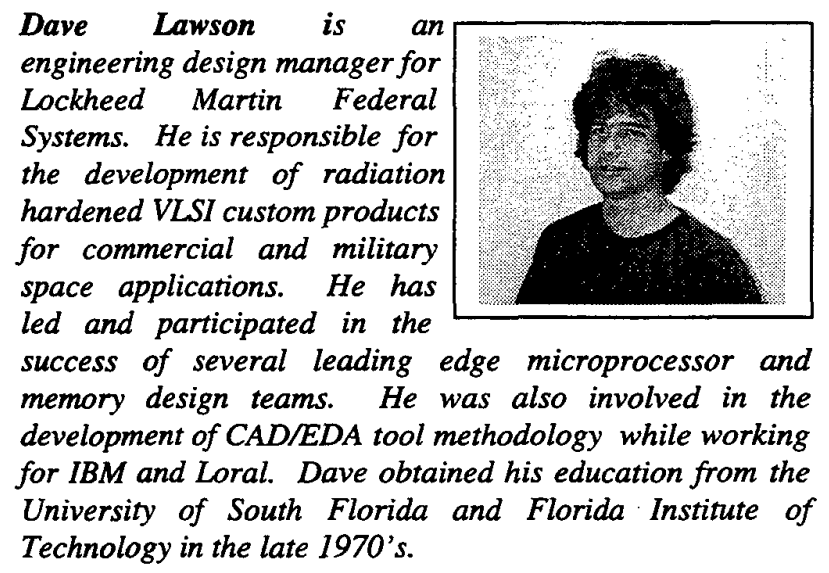

Tom Page began his career in NH\&S with GE AstroSpace (now part of Lockheed Martin Missiles \& Space), Valley Forge, PA , in 1986. While there, he performed nuclearhardening analysis and test on Milstar-I and -II, DSCS-III,GPS-IIR, and SBIRS. In 1996, he transferred to Lockheed Martin Federal Systems Manassas, VA, where he has

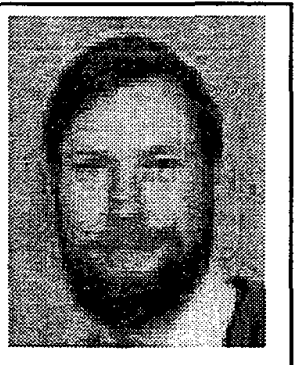
continued work in Radiation Assurance Engineering. Tom holds BS degrees in Chemistry and Electronic Engineering from Clemson University, SC, and a Masters degree in Engineering Science from Penn State University.

George Scandalis is a VLSI logic test engineer at Lockheed Martin Federal Systems' semiconductor facility in facility in Manassas, Virginia where he is responsible for test development of ASICs, processors, and MCMs. He

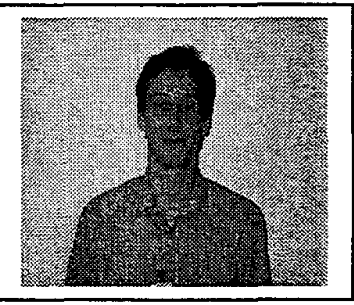
received his B.S. degree in Electrical Engineering from Virginia Polytechnic Institute.
Tom Scott is currently a lead characterization engineer at Lockheed Martin Federal Systems. $\mathrm{He}$ is responsible for radiation test and characterization of VLSI products for commercial and military space applications. He holds a MS degree in Physics from University of Maryland.

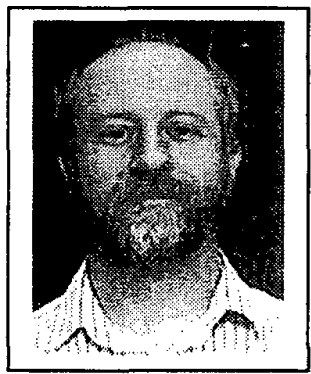

Parker Robinson is the Vice President of Engineering at insyte, responsible for technical oversight oversight of all projects, systems engineering and technology applications. Previously, he was Technical Director and Principal Systems Engineer for Honeywell Space Systems Electronic Product Engineering Group. He was with Honeywell for thirteen years before joining insyte, receiving Honeywell's Outstanding Engineer Award in 1989. He received a BSEE degree with honors from Yale University.

David Bain is a member of the engineering staff at insyte, with integrated circuit design and test responsibilities. During prior studies at the Center for Microelectronics Research at the University of South Florida, he worked on several projects performing device and process characterization. In 1992, he

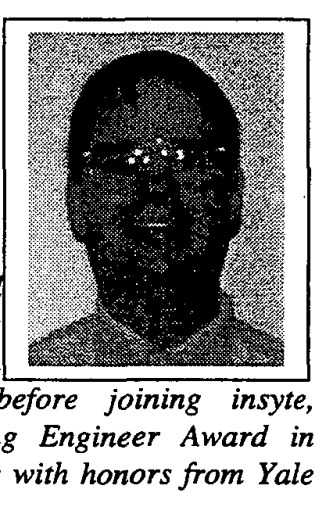
joined the Aerospace Corporation as a member of the technical staff working in the Microelectronics Evaluation and Verification Laboratory. He received his BSEE and MSEE from the University of South Florida. 